\title{
Thrombogenic Effect of High-Dose Aspirin in Rabbits
}

\author{
RELATIONSHIP TO INHIBITION OF VESSEL WALL SYNTHESIS \\ OF PROSTAGLANDIN I $_{2}$-LIKE ACTIVITY
}

\author{
J. G. Kelton, J. Hirsh, C. J. Carter, and M. R. Buchanan, Department of \\ Pathology, McMaster University Medical Centre, Hamilton, Ontario, Canada
}

\begin{abstract}
A B S T RACT Aspirin is a promising antithrombogenic agent. It inhibits the generation of thromboxane $\mathrm{A}_{2}$ by acetylating platelet cyclo-oxygenase. Aspirin also inhibits vessel wall production of $\mathbf{P G I}_{2}$ which is an inhibitor of platelet aggregation, and therefore is potentially thrombotic. To investigate these two opposing effects we studied the effects of aspirin upon fibrin accretion onto experimentally induced venous thrombi in rabbits and on the $\mathbf{P G I}_{2}$-like activity of vessel wall using the thrombin-induced $\left[{ }^{14} \mathrm{C}\right]$ serotonin release assay. A $200-\mathrm{mg} / \mathrm{kg}$ dose of aspirin significantly augmented thrombus size when compared to $(a)$ sodium salicylate administered in equal doses, $(b)$ aspirin in a $10-\mathrm{mg} / \mathrm{kg}$ dose or $(c)$ controls $(P<0.001)$. A $200-\mathrm{mg} / \mathrm{kg}$ dose of aspirin totally inhibited vessel wall $\mathbf{P G I}_{2}$-like activity whereas aspirin in a $10-\mathrm{mg} / \mathrm{kg}$ dose produced less inhibition, and $200 \mathrm{mg} / \mathrm{kg}$ sodium salicylate had no effect. Local instillation of tranylcypromine, an inhibitor of $\mathrm{PGI}_{2}$ formation, also significantly augmented thrombus size compared to saline-treated controls and totally inhibited the production of $\mathrm{PGI}_{2}$-like activity. The thrombogenic effect of high dose aspirin was lost if an interval of $2.5 \mathrm{~h}$ or longer elapsed between vessel damage and drug administration, indicating that in contrast to the platelet, the effect of aspirin on vessel wall prostaglandin synthesis is relatively short-lived. It is concluded that aspirin, in doses higher than those used clinically, can augment experimental thrombosis, presumably by inhibiting the synthesis of vessel wall PGI $_{2}$.
\end{abstract}

\section{INTRODUCTION}

Prostaglandins and related compounds play an important role in a number of pathophysiological proc-

This work was presented in part at Annual Meeting of the American Federation for Clinical Research San Francisco, Calif. 1978.

Received for publication 3 July 1978 and in revised form 24 July 1978. esses. Their contributions to hemostasis and thrombosis have not been fully defined but are diverse, and in some cases, opposing. Thus, thromboxane $A_{2}$, which is synthesized by platelets and other cells induces platelet aggregation whereas $\mathrm{PGI}_{2}$, which is synthesized by vascular wall cells, inhibits platelet aggregation (1).

Aspirin has been shown to inhibit the release reaction by acetylating platelet cyclo-oxygenase and so inhibit the synthesis of prostaglandins and thromboxane $A_{2}(2)$. This effect is achieved by a low concentration of aspirin and lasts for the life-span of the platelet. Aspirin also inhibits $\mathbf{P G I}_{2}$ synthesis by the vessel wall, an effect which could be potentially thrombogenic (3). Recently, it has been reported that the concentration of aspirin required to inhibit $\mathbf{P G I}_{2}$ formation by cultured smooth muscle cells of the vessel wall is much higher than that required to inhibit prostaglandin synthesis by platelets (4), a finding which suggests that in the doses used clinically, aspirin may inhibit platelet prostaglandin synthesis without affecting $\mathrm{PGI}_{2}$ formation by the vessel wall.

To investigate the potential thrombogenic effects of aspirin in vivo, we developed a model for quantitating fibrin accretion onto a thrombus caused by a standardized venous injury. The effects of aspirin in varying doses on thrombus size was assessed and related to its inhibition of synthesis of $\mathbf{P G I}_{2}$-like material by the vessel wall.

\section{METHODS}

Rabbit fibrinogen was prepared and labeled with ${ }^{125} \mathrm{I}$ (New England Nuclear, Boston, Mass.) by the method of Regoeczi (5). The clottability of the fibrinogen and the clottable radioactivity were $>90 \%$. Plasma fibrinogen was assayed using the method of Clauss.

Thrombosis model. New Zealand white rabbits, $2-3 \mathrm{~kg}$ in weight, were anesthetized with $30 \mathrm{mg} / \mathrm{kg}$ sodium pentobarbital, (MTC Pharmaceuticals, Hamilton, Ontario) administered intravenously through a marginal ear vein. The jugular vein was isolated bilaterally and a $30 \%$ stenosis produced 
in the proximal end of the vein. $1-\mathrm{cm}$ long vein segments were then milked free of blood and injured by applying bulldog clamps at either end of the segment for $30 \mathrm{~min}$. The clamps were then removed and blood flow restored.

$0.2 \mathrm{mg}{ }^{125}$ I-fibrinogen was infused intravenously through an ear vein $5 \mathrm{~min}$ after the clamps were removed. Blood samples ( $1.8 \mathrm{ml}$ whole blood into $0.2 \mathrm{ml}$ acid citrate containing 50 $\mu g$ aminocaproic acid [Lederle Laboratories, Pearl River, N. Y.]) were taken at time 0,3 , and $5 \mathrm{~h}$ through the carotid cannula for determination of fibrinogen concentration and radioactivity.

$30 \mathrm{~min}$ before the injury to the veins, the animals were infused with either a placebo (saline), sodium salicylate (pH 7.0), or aspirin dissolved in equimolar sodium carbonate buffer solution ( $\mathrm{pH} 7.0$ ). Less than $3 \%$ of the aspirin had hydrolyzed into sodium salicylate. $5 \mathrm{~h}$ after the initial vessel damage, the animals were injected with $1,000 \mathrm{U}$ of heparin to prevent postmortem clotting and sacrificed with an overdose of sodium pentobarbital. The vein segments were then clamped above and below the site of experimental thrombosis, removed, opened lengthwise, and then washed in a petri dish of saline. The radioactivity of the thrombi, and plasma samples, was measured in a model 1085 Nuclear-Chicago gamma counter (Nuclear-Chicago Corp., De Plaines, Ill.). The amount of fibrinogen accreted into the thrombi was calculated by relating the ${ }^{125} \mathrm{I}$ activity of the washed thrombi to the mean specific activity of the plasma fibrinogen during the experiment, as previously described (6).

The effect of tranylcypromine (Smith Kline \& French Laboratories, Philadelphia), an inhibitor of $\mathrm{PGI}_{2}$ synthesis (7), on injury-induced thrombosis was investigated in a similar manner. The jugular vein segments were temporarily occluded with sutures and emptied of blood. One vein was filled with $7.5 \mathrm{mM}$ tranylcyromine and the opposite side was filled with $0.5 \mathrm{ml}$ sodium chloride $(0.9 \%)$. After 10 min the sutures were released and blood flow restored. Experimental thrombosis was then induced as described.

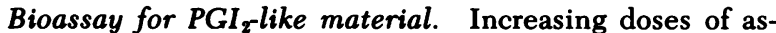
pirin or sodium salicylate were injected into the marginal ear vein of anesthetized rabbits. $1 \mathrm{~h}$ later, vein segments were dissected out, weighed, cut lengthwise, and then washed in Tyrode's albumin solution (3.5\% bovine albumin, Sigma Chemical Co., St. Louis, Mo., pH 7.35, osmolarity, 297 mM). Rings were cut from the vessel and incubated in $2.5 \mathrm{ml}$ of Tyrode's albumin solution. 4 min later, the suspension was centrifuged for $1 \mathrm{~min}$ at $12,000 \mathrm{~g}$. The supernatant fluid was removed and assayed immediately for $\mathrm{PGI}_{2}$-like material using a modification of the $\left[{ }^{14} \mathrm{C}\right]$ serotonin platelet release assay (8). Briefly, after washing in calcium- and albumin-free Tyrode's solution ( $\mathrm{pH} 6.2,297 \mathrm{mM}$ ), the platelets were incubated with 5-hydroxy-[ $\left[{ }^{14} \mathrm{C}\right]$ tryptamine creatinine sulphate ([14 $\mathrm{C}] 5 \mathrm{HT},{ }^{1}$ Amersham Corp., Arlington Heights, Ill.) in a final concentration of $1 \mathrm{mCi} / \mathrm{ml}$, then washed and resuspended in tyrode's albumin solution at a final platelet concentration of $400,000 / \mu \mathrm{l}$. Apyrase was added to degrade spontaneously released ADP. Imiprimine, in a final concentration to $1.6 \mathrm{mM}$, was added to an aliquot of the platelet suspension to block re-uptake of serotonin by platelets. The release reaction was induced by varying thrombin concentrations $(0.2,0.3,0.4$, 0.5 , or $0.8 \mathrm{U}$ ). This reaction was then terminated $60 \mathrm{~s}$ later by the addition of $500 \mu \mathrm{l}$ of $2 \%$ paraformaldehyde solution. The suspension was then centrifuged for $45 \mathrm{~s}$ at $12,000 \mathrm{~g}$ and the amount of $\left[{ }^{14} \mathrm{C}\right] 5 \mathrm{HT}$ released into the supernate determined.

Blood gas measurements. Arterial blood samples were taken into heparinized tubes for analysis of blood $\mathbf{p H}, \mathrm{PCO}_{2}$,

\footnotetext{
${ }^{1}$ Abbreviation used in this paper: $\left[{ }^{14} \mathrm{C}\right] 5 \mathrm{HT}, 5$-hydroxy[14 C]tryptamine.
}

and $\mathrm{PO}_{2}$ using a Radiometer Copenhagen Blood Gas Analyzer (Copenhagen, Denmark).

Statistical analysis. Unless otherwise stated, all statistical analyses were carried out using a multifactorial analysis of variance.

\section{RESULTS}

In the nontreated control animals thrombi contained $149 \pm 41.7 \mu \mathrm{g}$ fibrin $($ mean \pm SEM). Initial experiments demonstrated that thrombus size was not significantly different from control animals when the rabbits were pretreated with aspirin at doses of 5,10 , and $100 \mathrm{mg} / \mathrm{kg}$, but was larger than control at doses of $200 \mathrm{mg} / \mathrm{kg}$ or greater. Accordingly, the effects of aspirin at two dosage levels, 10 and $200 \mathrm{mg} / \mathrm{kg}$, were compared with placebotreated controls and a group treated with $200 \mathrm{mg} / \mathrm{kg}$ of sodium salicylate. Thrombus size was significantly greater in animals treated with $200 \mathrm{mg} / \mathrm{kg}$ of aspirin than in the other three groups which were not significantly different from each other, $P<0.001$ (Fig. 1). The effects of varying the interval between the administration of aspirin and producing damage to the jugular veins is shown in Fig. 2. A $200-\mathrm{mg} / \mathrm{kg}$ dose of aspirin potentiated thrombosis when it was administered $1 / 2$ $h$ before injury. This thrombotic effect was lost if an interval of 2.5 or $4 \mathrm{~h}$ elapsed between drug administration and injury.

When tranylcypromine was administered in doses which were large enough to inhibit the formation of $\mathrm{PGI}_{2}$-like material by the vessel wall, it was lethal. Accordingly, local instillation of the drug was used and

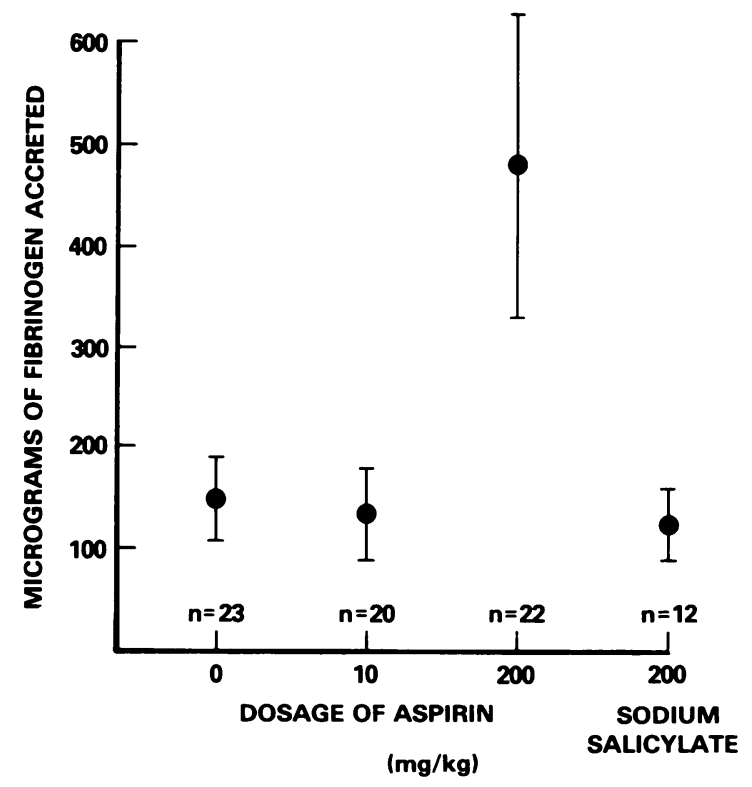

FigURE 1 Mean amount of fibrinogen (micrograms \pm SEM) accreted on thrombi formed in rabbits treated with saline (control), aspirin $(10 \mathrm{mg} / \mathrm{kg})$, aspirin $(200 \mathrm{mg} / \mathrm{kg})$, or sodium salicylate $(200 \mathrm{mg} / \mathrm{kg}) . n=$ number of animals in each group. 


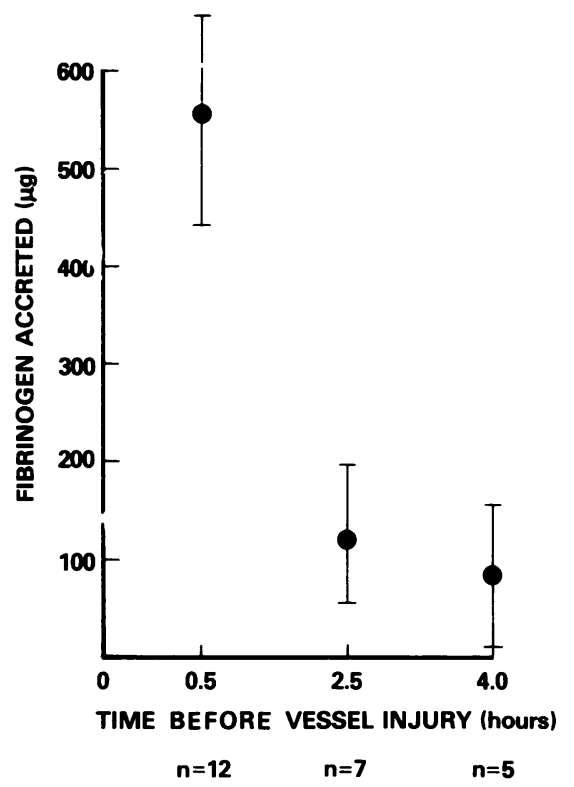

Figure 2 Mean amount of fibrinogen (micrograms \pm SEM) accreted on thrombi formed in rabbits treated with aspirin $(200 \mathrm{mg} / \mathrm{kg}) 0.5,2.5$, or $4 \mathrm{~h}$ previously. $n=$ number of animals in each group.

this resulted in an increase in fibrinogen accretion from $184.0 \pm 80.7 \mathrm{mg}($ mean $\pm \mathrm{SEM})$ in the saline-treated vessels to $591 \pm 174.2 \mathrm{mg}$ of fibrinogen in the tranylcypromine-treated vessels $(n=13 ; P<0.025$, paired $t$ test).

Veins from untreated rabbits produced a $\mathrm{PGI}_{2}$-like substance which inhibited thrombin-induced $\left[{ }^{14} \mathrm{C}\right]$ serotonin release from platelets. This inhibitor was labile at neutral or acidic $\mathrm{pH}$, its activity was abolished if the vessel was incubated in vitro in a $16-\mathrm{mM}$ solution of tranylcypromine for $10 \mathrm{~min}$, and was stable at alkaline $\mathrm{pH}$. The effects of pretreatment with aspirin, salicylate, or saline on $\mathrm{PGI}_{2}$-like activity of vessel wall supernate is shown in Fig. 3. The percent $\left[{ }^{14} \mathrm{C}\right] 5 \mathrm{HT}$ release of platelets incubated with Tyrode's solution is plotted on the abscissa, and the release from the platelets incubated with the treated vessel wall supernate is plotted on the ordinate. Each point represents two samples of platelets exposed simultaneously to either buffer control or test vessel supernate before induction of $\left[{ }^{14} \mathrm{C}\right] 5 \mathrm{HT}$ release by thrombin. Analysis of the amount of inhibition for each group of test samples compared to the simultaneously assayed control samples was carried out at all thrombin concentrations. The saline-treated vein segments produced a mean inhibition of $\left[{ }^{14} \mathrm{C}\right] 5 \mathrm{HT}$ of $58 \%$. The sodium salicylate treated veins produced a similar degree of inhibition (mean $64 \%$ ). A $10-\mathrm{mg} / \mathrm{kg}$ dose of aspirin produced less inhibition (mean 39\%; $P<0.05$ ) than either of the previous groups. Although a $200-\mathrm{mg} / \mathrm{kg}$ dose of aspirin produced no inhibition, the effect was significantly different from the previous three groups $(P<0.01)$.

No adverse changes were observed when the animals were infused with the aspirin or salicylate. The blood $\mathrm{pH}$ and $\mathrm{PCO}_{2}$ in the four groups was not significantly different and is not shown here.

\section{DISCUSSION}

It has been suggested that the formation of $\mathrm{PGI}_{2}$ by the vessel wall may be an important protective mechanism against thrombosis (9). The results of our experiments show that aspirin, when given in high doses, augments injury-induced thrombosis. This effect was not caused by changes in blood $\mathrm{pH}$ since these were slight and were also produced by sodium salicylate which was not thrombogenic. The findings do, however, support the concept that, when administered in large doses, aspirin potentiates thrombosis by inhibiting $\mathbf{P G I}_{2}$-like activity from the vessel wall. Furthermore, tranylcypromine augmented thrombosis and totally inhibited the production of $\mathrm{PGI}_{2}$-like activity in the assay system used.

The loss of thrombogenic effect of aspirin when the drug was administered at least $2 \mathrm{~h}$ before vessel damage suggests that the vessel wall cells were able to replace acetylated cyclo-oxygenase by synthesizing new enzyme. This is in contrast to the effect of aspirin on platelet prostaglandin synthesis which is irreversible presumably because the cells are anuclear and therefore incapable of synthesizing more enzyme.

Aspirin, in smaller doses which only partly inhibited

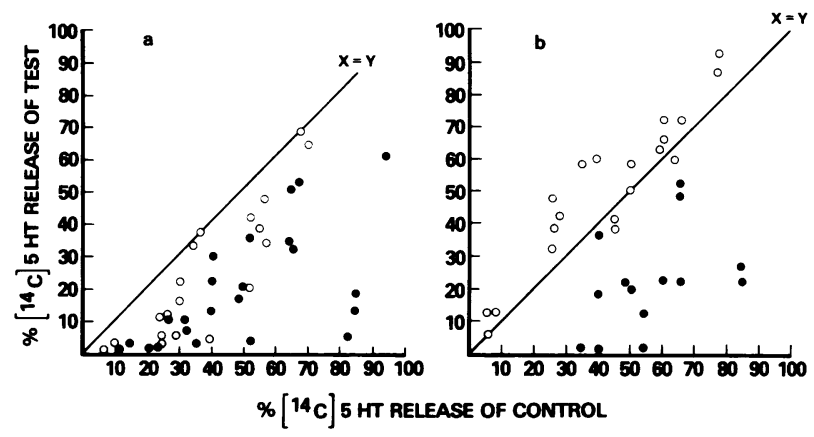

Figure 3 Percent thrombin-induced $\left[{ }^{14} \mathrm{C}\right] 5 \mathrm{HT}$ release from platelets incubated with supernates obtained from vessel walls (ordinate) plotted against percent thrombin-induced $\left[{ }^{14} \mathrm{C}\right] 5 \mathrm{HT}$ release from aliquots of the same platelet suspension incubated with an equivolume of Tyrode's solution (abscissa). The line $x=y$ represents the theoretical line formed when there is no inhibitory activity in the test supernate. Points below the line indicate that there is inhibition of $\left[{ }^{14} \mathrm{C}\right]$ serotonin release $(a)$ Release from platelets incubated with vessel wall supernates obtained from rabbits $30 \mathrm{~min}$ after treatment with saline $(\Theta)$ or $10 \mathrm{mg} / \mathrm{kg}$ aspirin $(O)$. (b) Release from platelets incubated with vessel wall supernates obtained from rabbits $30 \mathrm{~min}$ after treatment with $200 \mathrm{mg} / \mathrm{kg}$ sodium salicylate (๑) or $200 \mathrm{mg} / \mathrm{kg}$ aspirin $(\bigcirc)$. 
the formation of $\mathrm{PGI}_{2}$-like activity by the vessel wall did not augment thrombosis, presumably because enough prostaglandin was synthesized to protect against injury-induced thrombosis.

The dose of aspirin required to augment thrombosis is much higher than the dose used clinically for management of thrombosis and the dose required to inhibit platelet prostaglandin synthesis. This is consistent with the report by Baenziger et al. in which it was demonstrated that much higher concentrations of aspirin were required to inhibit prostaglandin synthesis by cultured vessel wall smooth muscle cells than to inhibit prostaglandin synthesis in platelets (4). It is unlikely, therefore, that aspirin would be thrombogenic when used in therapeutic doses, however, our findings raise the possibility that other inhibitors of prostaglandin synthesis which have a greater effect on the vessel wall could potentiate thrombosis.

\section{ACKNOWLEDGMENTS}

The authors thank L. Bilyk and J. Santos for their technical assistance.

This work was supported by grants from The Canadian Heart Foundation.

\section{REFERENCES}

1. Moncada, S., R. Gryglewski, S. Bunting, and J. R. Vane. 1976. An enzyme isolated from arteries transforms pros- taglandin endoperoxides to an unstable substance that inhibits platelet aggregation. Nature (Lond.). 263: 663665.

2. Roth, G. J., and P. W. Majerus. 1975. The mechanism of the effect of aspirin on human platelets. I. Acetylation of a particulate fraction protein. J. Clin. Invest. 56: $624-632$.

3. Villa, S., A. Callioni, and G. de Gaetano. 1977. Normal prostacyclin-like activity in vascular tissues from thrombocytopenic rats. Thromb. Res. 11: 701-704.

4. Baenziger, N. L., M. J. Dillender, and P. W. Majerus. 1977. Culture human skin fibroblasts and arterial cells produce a labile platelet-inhibitory prostaglandin. Biochem. Biophys. Res. Commun. 78: 294-301.

5. Regoeczi, E. 1970. Fibrinogen catabolism: kinetics of catabolism following sudden elevation of the pool with exogenous fibrinogen. Clin. Sci. (Oxf.). 38: 111-121.

6. Chiu, H. M., J. Hirsh, W. L. Yung, E. Regoeczi, and M. Gent. 1977. Relationship between the anticoagulant and antithrombotic effects of heparin in experimental venous thrombosis. Blood. 49: 171-184.

7. Gryglewski, R. J., S. Bunting, S. Moncada, R. J. Flower, and J. R. Vane. 1976. Arterial walls are protected against deposition of platelet thrombi by a substance (prostaglandin X). Prostaglandins. 12: 685-709.

8. Packham, M. A., M. A. Guccione, J. P. Greenberg, R. L. Kinlough-Rathbone, and J. F. Mustard. 1977. Release of ${ }^{14} \mathrm{C}$-serotonin during initial platelet changes induced by thrombin, collagen, or A23187. Blood. 50: 915-926.

9. Weksler, B. B., A. J. Marcus, and E. A. Jaffe. 1977. Synthesis of prostaglandin $I_{2}$ (prostacyclin) by cultured human and bovine endothelial cells. Proc. Natl. Acad. Sci. U. S. A. 74: 3922-3926. 